experiments with radioactive sulfur. J Biol Chem 130:67

20. Tateishi N, Higashi T, Naruse A, Nakashima K, Shiozaki H, Sakamoto Y 1977 Rat liver glutáthione: possible role as a reservoir of cysteine. J Nutr 107:51

21. Tietze F 1969 Enzymatic method for quantitative determination of nanogram amounts of total and oxidized glutathione. Anal Biochem 27:502

22. Zlotkin SH, Anderson GH 1982 The development of cystathionase activity during the first year of life. Pediatr Res 16:65

23. Zlotkin SH, Bryan MH, Anderson GH 1981 Cysteine supplementation to cysteine-free intraveous feeding regimens in newborn infants. Am $\mathbf{J}$ Clin Nutr 34:914
24. Zlotkin SH, Anderson GH 1982.Sulfur balances in intravenously fed infants: effect of cysteine supplementation. Am J Clin Nutr 36:862

25. The authors wish to acknowledge the technical help of Tracy Prater and the secretarial assistance of Neva Hepler.

26. This research was supported by Abbott Laboratories Grant 81380 and Biomedical Research Support Grant DHHS 2S07-RR05427-21.

27. Presented in part at the Annual Meeting of the Society for Pediatric Research, Washington, D.C., May 3-6, 1983.

28. Reprint requests should be addressed to: Dr. Michael Malloy, Department of Pediatrics, University of Texas Medical Branch, Galveston, TX 77550.

29. Received for publication December 1, 1983.

\title{
Food Protein-induced Enterocolitis: Altered Antibody Response to Ingested Antigen
}

\author{
PHILIP J. McDONALD, RANDALL M. GOLDBLUM, GREGGORY J. VAN SICKLE, AND \\ GERALDINE KEATING POWELL ${ }^{(32)}$ \\ Department of Pediatrics, Divisions of Gastroenterology and Immunology, University of Texas Medical Branch, \\ Galveston, Texas USA
}

\begin{abstract}
Summary
To evaluate the role of immunologic mechanisms in one specific syndrome of food intolerance in infants, food protein-induced enterocolitis, we measured class-specific serum antibodies to three food proteins, ovalbumin, soy, and cow milk, prior to diagnostic food challenges in $\mathbf{1 8}$ infants suspected to have this syndrome. Infants with positive challenge reactions to egg, soy, or cow milk had 5-10 times higher levels of IgA antibody directed against that food than did the infants with negative challenges. Levels of IgG antibody to soy and egg were also significantly higher (greater than 10-fold) in infants with positive challenge responses. There was no significant difference in levels of IgM food antibodies between the two groups. IgA anti-soy antibody levels rose in all 12 infants tested 2-10 weeks after a single soy feeding (challenge). However, IgM anti-soy antibody increased in the five infants who had a negative response to the challenge feeding and decreased in those seven with a positive response. The difference between the two groups was statistically significant $(P<0.01)$. Some correlation existed $(r=-0.68)$ between the increase in IgA anti-soy antibody and the decrease in IgM anti-soy antibody for infants with positive soy challenges. Although a pathogenic role for these antibodies is not proven, the findings suggest an altered immunologic response to ingestion of food antigens in infants with food protein-induced enterocolitis.
\end{abstract}

\section{Abbreviation}

FPIE, food protein-induced enterocolitis

Adverse reactions to cow milk or soy protein are common in infancy with an estimated incidence of 1 to $3 \%(5,11)$. Diverse gastrointestinal reactions have been described which include iron deficiency anemia associated with gastrointestinal blood loss (28), protein-losing enteropathy (26), malabsorption syndrome with defects in fat and/or carbohydrate absorption $(6,9,15)$, and a colitis-like syndrome $(12,17,20,22)$.
The pathogenic mechanisms in these reactions are undefined, but immunologic factors are frequently considered. Sensitization of $\mathrm{T}$ lymphocytes to cow milk antigens has been described in milk-sensitive infants (3). In addition, in some studies, increased serum antibodies to food proteins were thought to correlate with positive responses to oral cow milk challenge $(8,18,29)$. However, in other studies, no difference in serum antibodies was found between milk-sensitive and normal infants $(1,6,23)$. These contradictions may be related to variations in age and symptoms of the subjects, failure to confirm the diagnosis by a standardized oral challenge, or differences in the immunoassays utilized.

We attempted to define an immunological basis for one specific syndrome of infancy, FPIE, by correlating the levels of classspecific serum antibodies to three food proteins, ovalbumin, soy, and cow milk, with the response to a diagnostic oral challenge with the same three food proteins in infants suspected of having this syndrome. We also evaluated the change in anti-soy antibody titer in response to this oral challenge in a subgroup of these infants who received only a single soy feeding.

\section{MATERIALS AND METHODS}

Patient Selection. Approval for this study was obtained from the Human Research Committee at the University of Texas Medical Branch. Infants suspected of having FPIE were studied at the time of readmission for diagnostic food challenges. As described previously (20), the infants presented initially with vomiting and chronic diarrhea which continued when they were switched from cow milk to soy-based formulas. Enterocolitis was diagnosed because the stools contained mucus, blood and leucocytes in addition to carbohydrate. The symptoms resolved completely within 2-3 days when whole protein was removed from the diet (oral electrolyte solution and subsequently a formula containing casein hydrolysate; Nutramigen, Mead Johnson) and no pathogens associated with colitis were isolated. The usual clinical management includes maintaining these infants on a casein hydrolysate formula (with no additional foods) for at 
least 1 month to establish that stools remained normal with regard to frequency, consistency, and absence of blood and leukocytes and that normal weight gain ensued. These clinical findings eliminated other possible causes of chronic diarrhea. FPIE then would be considered to be likely in these infants and they would be admitted for oral challenges (cow milk and soy) to confirm this diagnosis. None of the infants studied had a history of immediate hypersensitivity-type symptoms such as upper respiratory symptoms, wheezing, or urticaria.

All infants admitted to the study fulfilled the following criteria: 1) age less than 1 year; 2) a history of prior oral exposure to soy and cow milk formula but not to egg white; 3) no history of immediate hypersensitivity-type reactions; 4) a normal weight gain for at least 1 month while receiving the casein hydrolysate formula only; 5) no immunizations or medications for 1 week prior to study; 6) a normal physical exam; 7) a negative stool examination for leukocytes and blood. Despite a history compatible with FPIE, eight of the 18 total infants subsequently had a negative response to oral challenges with all three antigens (egg, soy, cow milk) and thus provided a negative control group. Ten of the infants had a positive response to one or more of the challenges (Table 1).

The mean age at time of study was 5.4 months (range, 3-11 months). Although infants with positive milk challenges tended to be slightly younger than those with all negative challenges, there was no significant difference in age or length of time on casein hydrolysate formula for any of the groups listed (Table I). By history, the average age at onset of symptoms was 3.8 weeks (range, 1 day-12 weeks). Only two of the infants had been breast fed, one for 3 weeks and one for 7 weeks. There were 14 males and 4 females. Exposure to solid foods could not be excluded by history in four patients nor could the extent of exposure to cow milk and soy be established.

Oral Challenge Protocol. Baseline serum antibody titers were obtained before oral challenge. Using a single dose of $0.6 \mathrm{~g}$ protein $/ \mathrm{kg}$ body weight, the infants were given sequential oral challenges with three foods: egg white, soy formula; (Nursoy, Wyeth), and skim milk in that order. The egg challenge was to serve as a negative control, since by history none of the infants had been fed egg or egg-containing products. Following a negative challenge response, a minimum of $48 \mathrm{~h}$ was allowed to elapse before a subsequent challenge. Following a positive challenge response, a minimum of 5 days was allowed, and reattainment of baseline state was ensured by normal weight gain, stool consistency and frequency, and absence of blood and leukocytes in stools for at least 2 days.

Previous experience with this challenge method (20) indicated that diarrhea with blood and leukocytes occurs an average of 5 $\mathrm{h}$ postchallenge (range, $2-10 \mathrm{~h}$ ). If vomiting occurs, it is the earliest symptom, occurring an average of $2 \mathrm{~h}$ postchallenge (range, 1-2.5 h). Therefore, infants were monitored for $24 \mathrm{~h}$ after challenge for development of the following criteria: 1) symptoms of vomiting or diarrhea; 2) increase in peripheral polymorphonuclear leukocyte count of more than $4000 / \mathrm{mm}^{3}$ between a blood count drawn immediately before oral challenge and 6 to 8 $h$ after challenge; 3 ) the appearance of blood (hemoccult) in the stool; 4) appearance of leukocytes in Hansel-stained smears of

Table 1. Relationship between food challenge results and age at time of challenge

\begin{tabular}{lcc}
\hline & $n$ & Age (months) \\
\hline $\begin{array}{l}\text { Negative challenge with all three } \\
\text { foods } \\
\begin{array}{l}\text { Positive challenge with one or } \\
\text { more foods }\end{array}\end{array}$ & 8 & $6.3 \pm 2.6$ \\
$\begin{array}{l}\text { Positive soy challenge } \\
\text { Positive cow milk challenge }\end{array}$ & 8 & $5.1 \pm 1.7$ \\
Positive egg challenge & 5 & $5.2 \pm 1.9$ \\
\end{tabular}

* Mean \pm SD. stool mucus; 5) appearance of Charcot-Leyden crystals or eosinophilic debris in the stool (21). To allow blinded judgment of challenge results, all five criteria noted were evaluated following the challenge by an investigator not familiar with the infant's history. The challenge reaction was considered positive if three or more criteria were present, negative if one or less, and equivocal if two criteria were present. Data from equivocal challenges were not considered in the analysis. None of the infants developed anaphylaxis, rhinitis, wheezing, or urticaria following food challenges. Infants who demonstrated serum immunoglobulin concentrations below normal were excluded from analysis.

Chronic Tolerance. Infants with a negative acute challenge to milk or soy were placed on the appropriate formula and evaluated for a follow-up period of 4 days in the hospital and for at least 2 additional months as an outpatient. Chronic tolerance to the formula was defined as follows: 1) absence of adverse gastrointestinal symptoms (vomiting, diarrhea); 2) normal stool examination (consistency, absence of blood or fecal leukocytes); 3) no change in serum protein electrophoresis, white blood count, or differential; 4) weight gain appropriate to caloric intake; 5) no decrease in the serum xylose absorption test, performed at the time of outpatient follow-up, as compared to the prechallenge value. None of the infants evaluated for chronic tolerance showed a positive delayed reaction to a formula they had tolerated acutely.

Subgroup of Infants Studied for Antibody Response to a Single Oral Soy Feeding. Infants with a negative response to cow milk (whether soy challenge was positive or negative) were discharged on a cow milk-based formula; those with positive responses to both soy and cow milk were discharged on Nutramigen. This provided the opportunity to compare the change in anti-soy antibody titers in a subgroup of 12 infants, seven of whom had challenge-proven soy protein-induced enterocolitis and five who did not. All had received a single oral dose of soy. As a pilot study (Fig. 1) suggested that the antibody titers were stable between 2 and 12 weeks following challenges, these follow-up titers were drawn at the time of the infants' next visit in the outpatient clinic within that time interval. The mean interval between titers for the positive soy responses was $8 \pm 4$ weeks and for the negative soy responses $4 \pm 1$ weeks.

Antibody Determination Method. Serum anti-ovalbumin, anti-
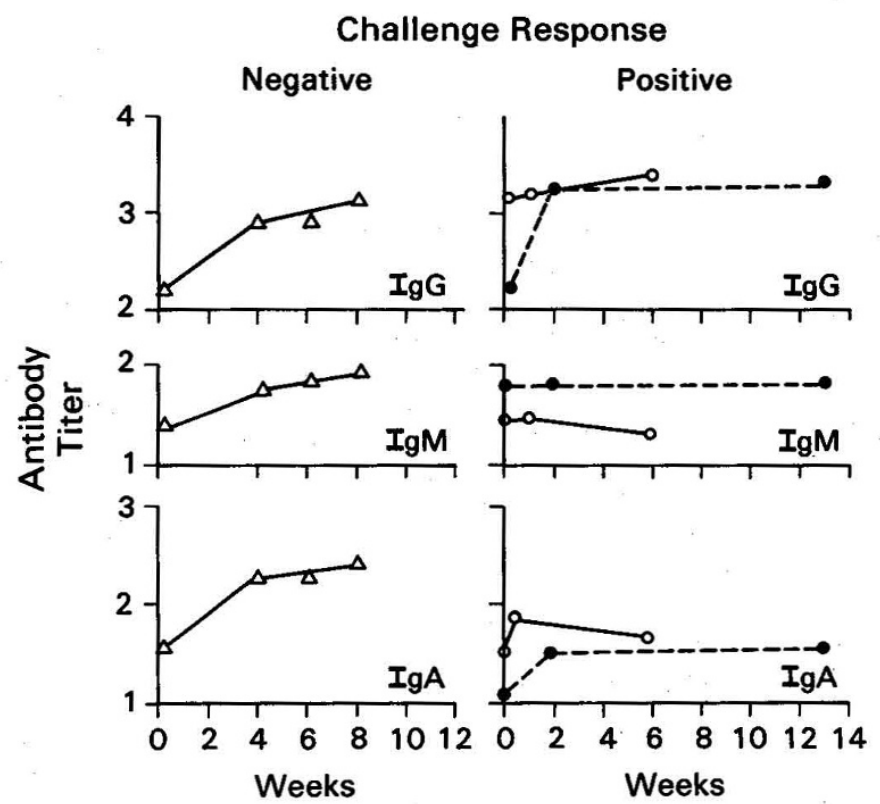

Fig. 1. Time course of anti-soy antibody titers after a single oral challenge with soy protein; pilot study in three patients, two with positive responses and one with a negative response. Percentage of pooled adult serum standard, expressed as logarithm to the base $10(1=10 \% ; 2=$ $100 \% ; 3=1,000 \% ; 4=10,000 \%$ ). 
soy protein, and anti-cow milk protein antibody determinations were performed by a micromodification of the enzyme-linked immunoassay described previously (2). Cooke microtiter plates were coated with either ovalbumin, $52.5 \mu \mathrm{g} /$ well (Sigma), soy protein, $52.5 \mu \mathrm{g} /$ well (Edi-Pro-A, Mead Johnson), or skim milk

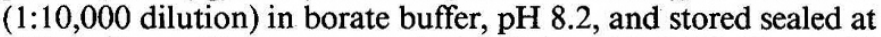
$4^{\circ} \mathrm{C}$ until use. Plates were washed 8 times with $0.5 \%$ Tween 20 in $0.15 \mathrm{~N}$ sodium chloride immediately before use and between subsequent incubations. Serum samples or pooled serum standard were applied in 4-fold dilutions to the plates, which were then covered and gently rocked at $22^{\circ} \mathrm{C}$ for 4 to $6 \mathrm{~h}$. Classspecific rabbit anti-human IgG, IgM, or IgA (Dako) conjugated to alkaline phosphatase was next added for overnight incubation at $22^{\circ} \mathrm{C}$. The enzymatic activity in the well was estimated using $p$-nitrophenyl phosphate as substrate. Optical density of the product was measured on an automated enzyme-linked immunosorbent assay reader (Dynatech) and plotted against the log 10 of the serum dilution. On each plate, wells without antigen coat and wells without serum served as controls. These were always less than $10 \%$ of maximum activity of experimental wells. The specificity of the anti-immunoglubulin reagents was established in antibody assays using sera from patients deficient in one or more immunoglobulin class (in enzyme-linked immunoassays assays for antibody against diptheria and tetanus toxoids). The titers of a pool of normal adult serum was determined from the dilution producing half-maximum enzyme activity and were as follows: anti-ovalbumin, IgG, 1:174, IgM, 1:16, IgA, 1:21; antiEdi-Pro-A (soy), IgG, 1:18, IgM, 1:25, IgA, 1:12; anti-skim milk, $\operatorname{IgG}, 1: 42$, IgM, 1:23, IgA, 1:16. The antibody values for the patients' samples were calculated as percentage of activity of the serum pool assayed on a same plate. The results for food antibodies in patient samples are reported and analyzed as $\log 10$ of the percentage of the serum pool. Statistical analysis utilized Student's $t$ test and regression analysis.

\section{RESULTS}

Antibody titers obtained immediately prior to diagnostic challenge are shown in Figure 2. The geometric mean of the IgG anti-soy antibody concentration for infants with a positive soy challenge $(1072 \%)$ was significantly higher $(P<0.01)$ than the mean for patients with negative challenges (110\%). A significant difference in mean IgG antibody titers between positive and negative egg challenge responders was also seen ( 355 versus $4 \%$, $P<0.001)$. Infants with positive challenge reactions had higher mean IgA food antibody titers for all three foods. This difference reached statistical significance for soy responders (170 versus $20 \%, P<0.004)$ and egg responders (35 versus $3 \%, P<0.003)$ but was less significant for milk (44 versus $9 \%, P<0.06$ ).

Baseline anti-food antibody of the IgM class also tended to be higher in positive responders but this difference did not reach statistical significance for any food. Considerable overlap between the titers of infants with positive and negative challenges was noted for all classes of antibody to most antigens. Only for IgG class antibody to egg ovalbumin (to which the majority of infants had no exposure) was the positive challenge group clearly distinguishable from the negative group.

The antibody titers to a specific food in patients with all negative challenges (presumably negative control group) were not different from those of patients who had a negative challenge to that food but had positive responses to one or more other foods.

Antibody Response to Single Oral Soy Challenge. The change in antibody titer following a single oral challenge with soy protein in the 12 patients evaluated in this way is shown in Figure 3. IgA anti-soy antibody titers tended to rise after both positive and negative challenges, with no significant difference between the two groups. The mean IgG antibody titers did not change following negative oral soy challenges. Although four of the seven patients with positive challenges showed a rise in IgG titer, the
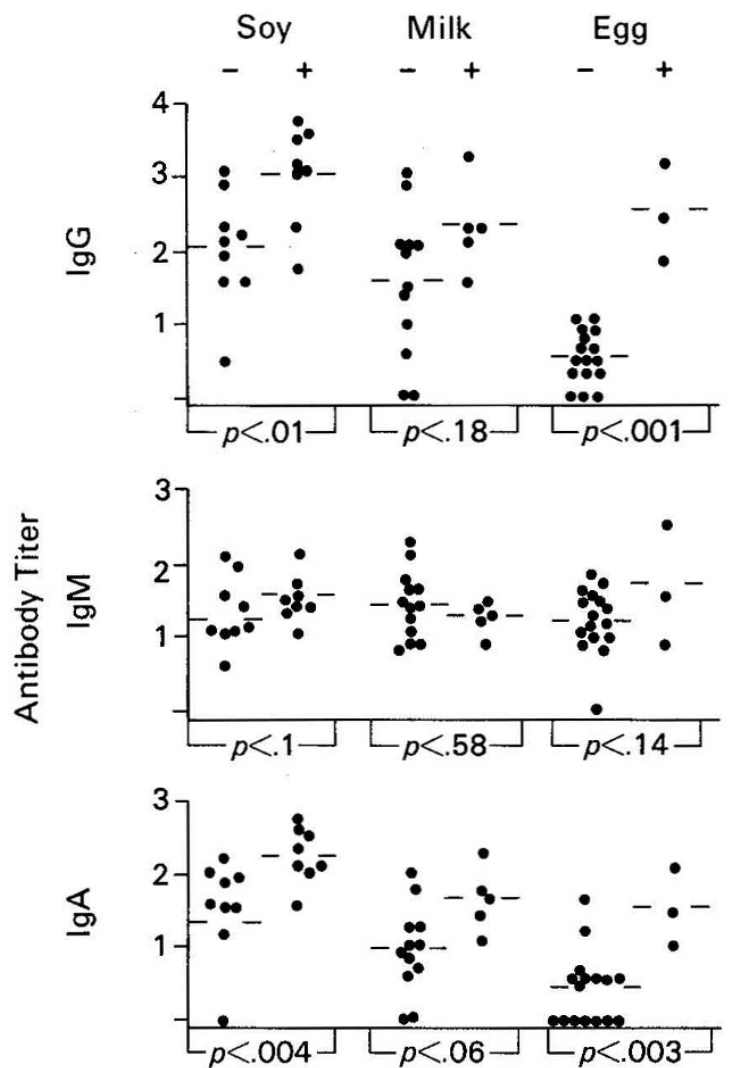

Fig. 2. Antibody titers to soy, cow milk, and egg (ovalbumin) of the $\mathrm{IgG}, \operatorname{IgM}$, and $\mathrm{IgA}$ class in the serum of infants prior to diagnostic oral challenges with the same antigens. -, negative challenge response; + , positive challenge response. Percentage of pooled adult serum standard, expressed as logarithm to the base $10(1=10 \% ; 2=100 \% ; 3=1,000 \%$; $4=10,000 \%)$.

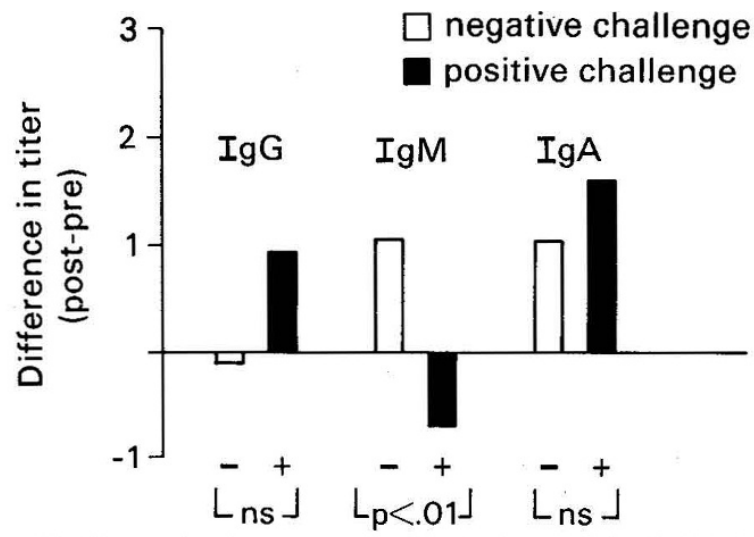

Fig. 3. Change in the anti-soy antibody titers of the $\mathrm{IgG}, \mathrm{IgM}$, and IgA class following a single oral challenge with soy protein. Change is expressed as the logarithm to base 10 of the difference in antibody titer (percentage of the serum pool) before and after challenge.

change in titer (postchallenge-prechallenge) was not statistically different from patients with negative challenges.

An increase in IgM anti-soy antibody was found in infants with a negative response to oral soy challenge. In contrast, a decrease in IgM anti-soy antibody was seen in infants with a positive challenge. The difference in IgM antibody response between the two groups was statistically significant $(P<0.01)$.

We attempted to correlate the change in antibodies of the various classes by regression analysis. There appeared to be some inverse correlation $(r=-0.68, P<0.09)$ between the increase in IgA antibody and the decrease in IgM anti-soy antibody for 
the seven infants with a positive challenge (Fig. 4). This correlation was not present in five infants with a negative challenge.

Since patients with a positive challenge had higher baseline anti-soy antibody titers, we evaluated the correlation between the prechallenge titer and the change in antibody titer following challenges. Only one pair of data analyzed this way showed any correlation; the decrease in the IgM antibody titer in patients with positive challenges was inversely correlated with the height of the prechallenge IgM titer in these patients $(r=-0.86, P<$ $0.04)$.

\section{DISCUSSION}

Previous studies examining antibodies to protein in infants with adverse reactions to formulas have been complicated by variability in symptoms and patient age, and failure to confirm the diagnois by a defined oral challenge. Since the mechanism for adverse reactions to food proteins in infants is unknown various immunological mechanisms may be involved in different symptom complexes. The purpose of this study was to evaluate antibody titers and antibody response to oral exposure in one well defined symptom complex, FPIE $(12,17,19,20,22)$. This symptom complex would not fit into the "reaginic" class of food hypersensitivity, defined by May as being associated with immediate hypersensitivity symptoms, IgE antibodies, and positive skin tests, but rather into his "non-reaginic food hypersensitivity" category, manifested as chronic diarrhea, malabsorption, and gastrointestinal blood loss, and not associated with IgE antibodies or positive skin tests (4). In each infant studied, the diagnosis was established or rejected on the basis of a uniform oral challenge procedure previously described (20). Those infants with negative challenges served as a disease control group since their previous symptoms and dietary manipulations were similar to the group with food protein-induced enterocolitis. This control group included infants with negative responses to all three antigens as well as infants who had a negative challenge to the antigen in question but a positive challenge to another protein. The results indicate that certain classes of antibodies to some food proteins are increased in the serum of infants who display a positive response to oral challenge with the same proteins. The increase was significant despite a study design which might minimize differences between the two groups.

The immunoglobulin class spectrum varied somewhat with the food involved. IgG antibodies were significantly increased for soy and egg protein (ovalbumin) but not for cow milk. However, IgA antibodies were increased for all three foods and IgM for none. The extent of the increases, while highly significant for the group data, does not allow clear discrimination of indi-

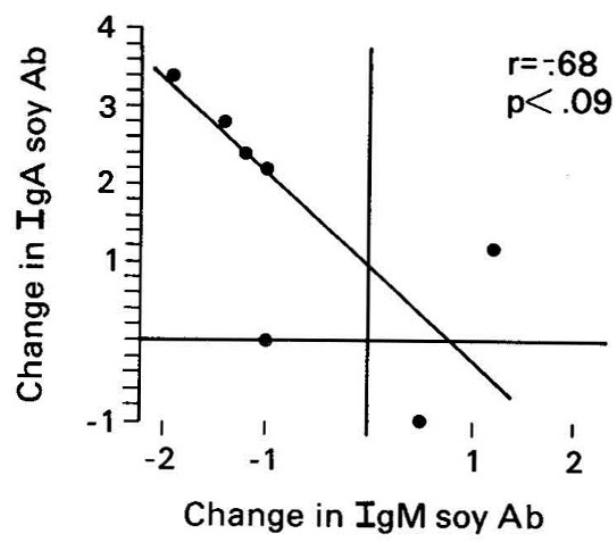

Fig. 4. Change in anti-soy antibody $(A b)$ titer after a single positive oral challenge with soy; correlation between change in IgA antibody and IgM antibody. Change is expressed as the logarithm to base 10 of the difference in antibody titer (percentage of serum pool) before and after challenge. vidual patients except for IgG antibodies to ovalbumin. This particular difference may have been enhanced by our attempts to select infants with no history of exposure to this food. One could not therefore reliably predict challenge outcome based solely on antibody titer. These results are in disagreement with some studies in which predictive value of antibodies is suggested $(8,18,29)$ but confirm the considerable overlap of data found in other studies $(1,6,23)$.

Despite the fact that specific questions regarding the infants' previous ingestion of solid foods were answered negatively by all but four parents, many infants did have serum anti-ovalbumin antibody of IgM and IgA class, suggesting previous exposure to this antigen. This finding underscores the unreliability of dietary history in food intolerances.

The significance of serum antibodies in the pathogenesis of food protein intolerance is not clear. It frequently is assumed that normal infants have increased levels of serum antibodies to food protein because of enhanced intestinal absorption of antigenic dietary proteins (7). A further increase in absorption has been hypothesized in food-intolerant infants (27). There are, however, no data in humans to substantiate either of these assumptions. There is increasing evidence in experimental animals that sensitization of the lymphoid tissue of the gastrointestinal tract may lead to systemic (30) as well as local antibody responses or may cause tolerance to parenterally administered antigen $(13,24)$. Furthermore, this route of sensitization (priming) leads to a characteristic isotype pattern in the subsequent response, with predominance of $\operatorname{IgA}(10)$. It is therefore interesting in our study that increases in antibodies to food protein were most commonly of the IgA class. This is especially striking in view of the slow development of serum $\operatorname{IgA}$ concentration in infancy. We also found that affected infants had increased levels of serum IgG antibodies against two of the food antigens. The age of the infants and the low level of food antibodies in adult serum make a transplacental origin of this antibody unlikely. It has been shown in experimental animals that gastrointestinal sensitization can lead to an IgG as well as IgA response, although parenteral immunization is more selective for the $\operatorname{IgG}$ class (10).

We next examined the effect of a single oral feeding of soy proteins on the serum anti-soy antibody level in seven infants with soy-induced enterocolitis and compared them with five infants who had a similar clinical presentation but negative soy challenge. This evaluation of antibody response to a single oral feeding in previously immunized infants could only be carried out for soy, since infants with a negative cow milk challenge were placed on milk chronically and the majority of infants challenged with ovalbumin did not have a previous exposure to that antigen. The change in IgG or IgA antibody to soy protein was not significantly different between the two patient groups. However, the difference in IgM antibody response between the two groups was dramatic. Patients with a negative oral challenge to soy protein demonstrated an increase in IgM antibodies while those with positive challenge had a decrease in this class of antibody. The decrease in IgM antibody to soy protein in infants with FPIE is consistent with a secondary response which could follow either local or systemic priming (10). However, the increase in IgM antibody to this protein in infants with a negative response to oral soy challenge would suggest a primary type of response despite an unequivocal history of previous oral exposure and the presence of some serum anti-soy antibodies of all three classes prior to challenge. Perhaps these differences might best be explained by differences in T lymphocyte regulatory effects. In general, the presence of sensitized $T$ lymphocytes with helper function would tend to promote a switch to the IgG and IgA isotypes and reduce IgM antibody production. The quantitative correlation between the decrease in anti-soy antibody of the IgM class with the rise in the IgA class in the infants with positive challenge response may offer support for this mechanism. We recently found further evidence for potential $\mathrm{T}$ lymphocyte involvement by demonstrating enhanced blastogenic response to 
soy protein in cultures of lymphocytes from infants with FPIE (25).

Alternatively, the difference in the antibody response to oral soy protein could perhaps be attributed to the time of development of a serum suppressor factor as described by Kagnoff in mice orally immunized with sheep red blood cells (14). His experiments showed an enhanced IgG and IgA antibody response and a decrease in IgM response to a parenteral challenge administered early in the course of oral immunization. After prolonged feeding of the same antigen; however, the IgA and IgG antibody responses to parenteral challenge were also reduced.

The present study does not provide evidence concerning a pathogenic role for serum antibodies in food protein-induced enterocolitis. Our results do suggest that infants with this entity have altered immunologic responses to ingested antigens. We at present favor the hypothesis that sensitization for this response occurs within the gastrointestinal lymphoid tissue and that the altered responses in affected infants may represent a breakdown or delay in development of those mechanisms which normally mediate systemic tolerance to antigen presented by this route. This alteration may also lead to the enhanced lymphocyte responses cited previously (25). We cannot, however, exclude the alternate hypothesis that the changes in baseline serum antibodies and in IgM anti-soy antibodies following challenge were secondary to persistent systemic absorption of intact antigen by the infants who continue to manifest a positive response to oral challenge. Further studies quantitating intestinal absorption of antigens in infants and correlating this absorption with development of FPIE are necessary to distinguish between these two hypotheses.

\section{REFERENCES AND NOTES}

1. Ahlstedt S. Carlsson B, Fallstrom SP, Hanson LA, Holmgren J, Lindin-Janson J, Lindblad BS, Jodal U, Kaijser B, Sohl-Akerlund A, Wadsworth C 1977 Antibodies in human serum and milk induced by enterobacteria and food proteins. In: Ciba Foundation Symposium 46-Immunology of the Gut. Elsevier/Excerpta Medica North-Holland, Amsterdam, pp 115-134

2. Ahlstedt S, Carlsson B, Hanson LA, Kaijser B, Mattsby-Baltzer I, SohlAkerlund A 1978 Application of the ELISA for determination of immunoglobulin class specific antibodies. Scand J Immunol 8:119 [Suppl 7]

3. Ashkenazi A, Levin S, Idar D, Ayala O, Rosenberg I, Handzel Z 1980 In vitro cell-mediated immunologic assay for cow's milk allergy. Pediatrics 66:399

4. Bock SA, May CD 1981 True manifestations of sensitivity reactions to foods and the associated immunologic findings. In: Ogra PL, Bienenstock J (eds). The Mucosal System in Health and Disease. Report of the Eight-First Ross Conference on Pediatric Research. Ross Laboratories, Columbus, OH, pp $114-118$

5. Collins-Williams C 1956 Incidence of milk allergy in pediatric practice. J Pediatr 48:39

6. Dannaeus SG, Johansson SGO, Foucard T, Ohman S 1977 Clinical and immunological aspects of food allergy in childhood. I. Estimation of IgG, IgA and IgE antibodies to food antigens in children with food allergy and atopic dermatitis. Acta Paediatr Scand 66:31

7. Eastham EJ, Lichanco T, Grady MI, Walker WA 1978 Antigenicity of infant formulas: role of immature intestine on protein permeability. J Pediatr 93:561

8. Freier S, Kletter B 1972 Clinical and immunological aspects of milk protein intolerance. Aust Pediatr J 8:140

9. Freier S, Kletter B, Gery. I, Lebenthal E, Geifman M 1969 Intolerance to milk protein. J Pediatr 75:623

10. Fuhrman J, Cebra JJ 1981 Special features of the priming process for a secretory IgA response-B cell priming with cholera toxin. J Exp Med 153:534

11. Gerrard JW, MacKenzie JWA, Goluboff N, Garson JZ, Maningas CS 1973 Cow's milk allergy: prevalence and manifestations in an unselected series of newborns. Acta Paediatr Scand Suppl 234:1

12. Gryboski JD 1967 Gastrointestinal milk allergy in infants. Pediatrics 40:354

13. Hanson DG, Vaz NM, Laia LCS, Hornbrook MM, Lynch JM, Roy CA 1977 Inhibition of specific immune responses by feeding protein antigens. Int Arch Allergy Appl Immun 55:526

14. Kagnoff MF 1978 Effects of antigen-feeding on intestinal and systemic immune responses. III. Antigen-specific serum-mediated suppression of humoral antibody responses after antigen feeding. Cell Immunol 40:186

15. Kilby A, Walker-Smith JA, Wood CBS 1975 Small intestinal mucosa in cow's milk allergy. Lancet 1:531

16. Kuitunen P, Visakorpi JK, Savilahti E, Pelkonen P 1975 Malabsorption syndrome with cow's milk intolerance: clinical findings and course in 54 cases. Arch Dis Child 50:351

17. Lapin JH, Weissberg WW 1948 Sigmoidoscopy in the diagnosis of allergic colitis. Am J Dis Child 76:78

18. May CD, Remigio L, Bock SA 1980 Usefulness of measurement of antibodies in serum in diagnosis of sensitivity to cow milk and soy proteins in early childhood. Allergy 35:301

19. McDonald PJ, Powell GK, Goldblum RM 1982 Serum D-xylose absorption tests: reproducibility and diagnostic usefulness in food-induced enterocolitis. J Pediatr Gastroenterol Nutr 1:533

20. Powell GK 1978 Milk and soy induced enterocolitis of infancy: clinical features and standardization of challenge. J Pediatr 93:553

21. Rosenblum AH, Rosenblum P 1952 Gastrointestinal allergy in infancy-significance of eosinophiles in the stools. Pediatrics 9:311

22. Rubin MI 1940 Allergic intestinal bleeding in the newborn: a clinical syndrome. Am J Med Sci 200:385

23. Saperstein S, Anderson OW, Goldman AS, Kniker WT 1963 Milk allergy. III Immunological studies with sera from allergic and normal children. Pediatrics 32:580

24. Thomas HC, Parrott DMV 1974 The induction of tolerance to soluble protein antigen by oral administration. Immunology 27:631

25. Van Sickle GJ, Powell GK, Goldblum RM, McDonald PJ 1981 Food protein induced enterocolitis: correlation between oral challenge and lymphocyte transformation induced by specific food proteins. Pediatr Res 15:549

26. Waldman TA, Wochner RD, Laster L, Gordon RS 1967 Allergic gastroenteropathy. N Engl J Med 276:761

27. Walker WA, Isselbacher KJ 1974 Uptake and transport of macromolecules by the intestine: possible role in clinical disorders. Gastroenterology 67:531

28. Wilson JF, Lahey ME, Heiner DC 1974 Studies on iron metabolism. V Further observations on cow's milk-induced gastrointestinal bleeding in infants with iron-deficiency anemia. J Pediatr 84:335

29. Wilson JF, Heiner DC, Lahey ME 1962 Studies on iron metabolism. J Pediatr 60:787

30. Wostmann BS, Pleasants JR, Bealmear P 1971 Dietary stimulation of immune mechanisms. Fed Proc 30:1779

31. This work was supported by National Institute of Child Health and Human Development, Contract NOI-HG-9-2834. Dr. McDonald was the recipient of a McLaughlin Foundation Research Training Fellowship. Patients were studied on the Clinical Research Center supported in part by Grant RR073 from the General Clinical Research Centers Program of the Division of Research Resources, National Institutes of Health. This work was presented in part to the 50th Annual Meeting of the Society for Pediatric Research, San Francisco, April 1981

32. Correspondence should be addressed to Geraldine K. Powell, M.D., Associate Professor, Department of Pediatrics, Division of Gastroenterology, University of Texas Medical Branch, Galveston, TX 77550.

33. Received for publication July 7, 1983

34 . Accepted for publication November 29,1983 